\title{
Pilot testing an intervention to educate and promote nutritious choices at food pantries
}

\author{
Sarah L. McKee ${ }^{1} \cdot$ Eminet Abebe Gurganus $^{1} \cdot$ Abiodun T. Atoloye $^{2} \cdot$ Ran Xu $^{3} \cdot$ Katie Martin $^{4} \cdot$ Marlene B. Schwartz $^{1,2}$
}

Received: 14 July 2020 / Accepted: 16 April 2021 / Published online: 25 May 2021

(C) The Author(s) 2021

\begin{abstract}
Aim This study aimed to assess the impact of the Supporting Wellness at Pantries (SWAP) system on client food selections at a food pantry.

Subject and methods In a pre-post comparison study design, a client-choice food pantry implemented SWAP by reorganizing its inventory to promote healthy options. Each product was ranked as "choose often" (green), "sometimes" (yellow), or "rarely" (red) based on saturated fat, sodium, and sugar. Signage was added to indicate each item's SWAP rank and healthier foods were placed at eye level. Client food baskets were assessed at time $1(n=121)$ and time $2(n=101)$. The proportions of green and red foods selected were compared using regression analyses.

Results The regression analyses showed that the proportion of green foods selected by clients increased by $11 \%(p<0.001)$ and the proportion of red foods selected decreased by $7 \%(p<0.001)$ after SWAP was implemented $(n=222)$.

Conclusions SWAP has the potential to positively shift client choices among the items available in a food pantry setting. SWAP is one component of a suite of changes to the charitable food system that have the potential to alleviate food insecurity, improve diet quality, and assist clients in managing diet-related diseases.
\end{abstract}

Keywords Food pantry $\cdot$ Food pantry clients $\cdot$ Charitable food $\cdot$ SWAP $\cdot$ Food selection

\section{Introduction}

Food insecurity, defined as insufficient or inconsistent access to safe and nutritious food due to limited resources, is experienced by $11 \%$ of U.S. households (Coleman-Jensen et al. 2018; USDA ERS 2019). People who live in low-income households have lower access to healthy food (Andreyeva et al. 2015; Duffy et al. 2009; Walker et al. 2010) and are consequently faced with increased risk for chronic, dietrelated diseases compared to higher income Americans

Marlene B. Schwartz

marlene.schwartz@uconn.edu

1 Department of Human Development and Family Sciences, University of Connecticut, Storrs, CT 06269, USA

2 Rudd Center for Food Policy and Obesity, University of Connecticut, Hartford, CT 06103, United States

3 Department of Allied Health Sciences, University of Connecticut, Storrs, CT 06269, USA

4 Foodshare Institute for Hunger Research \& Solutions, Bloomfield 06002, CT, USA
(Robaina and Martin 2013; Weinfield et al. 2014). The U.S. food banking system (also known as the charitable or emergency food system) is a network of food banks (i.e., regional organizations that source, warehouse, and distribute food) and community agencies such as food pantries (i.e., smaller, local organizations that order from food banks and receive donated food from other sources). Many households with food insecurity use the food banking system, either alone or in combination with other federal food assistance programs such as the Supplemental Nutrition Assistance Program (SNAP), to meet their food needs (Bhattarai et al. 2005; Daponte 2000; Weinfield et al. 2014).

In the US, over 200 food banks and 49,000 food pantries are associated with Feeding America, a national network that reported serving 4.2 billion meals to 40 million people in 2019 (Feeding America 2020). This network has untapped potential to alleviate food insecurity, improve diet quality, and assist clients in managing diet-related diseases (Martin et al. 2013; Schwartz and Seligman 2019; Seligman et al. 2015). Once considered "emergency" relief organizations, food pantries can be a major food source for their clients, with data suggesting that clients seek assistance once a week or more (Bhattarai 
et al. 2005; Cooksey-Stowers et al. 2019a, b; Weinfield et al. 2014). However, there is also evidence that the nutritional quality of the food available in the food banking system needs improvement (Huerbin et al. 2019; Simmet et al. 2017a, b). A survey of 230 clients found high levels of support for interventions to bring more healthy items into food pantries (Cooksey-Stowers et al. 2019a). In a related study, food pantry staff and volunteers viewed themselves as having an important role in improving the nutritional quality of pantry inventory and believed that their clients would appreciate more nutrition information (Cooksey-Stowers et al. 2019b).

The Supporting Wellness at Pantries (SWAP) system was developed with input from food pantry clients, staff, and volunteers (Martin et al. 2019). SWAP utilizes a stoplight nutrition ranking system based primarily on saturated fat, sodium, and sugar levels due to the association between these nutrients and diet-related diseases. SWAP combines multiple strategies to influence behavior: (a) color-coded signage on pantry shelves to help clients interpret nutrition information; (b) simple messaging to identify which items to choose "often" (green), "sometimes" (yellow), and "rarely" (red); and (c) prominent placement of the healthiest foods.

In a pilot test of the SWAP system, the majority of pantry staff and volunteers found it easy to use and believed that it helped staff obtain healthier food from the food bank and other donors (Martin et al. 2019). A related study among six food pantries found an improvement in the nutritional quality of pantry inventory after one year of implementing SWAP (Cooksey-Stowers et al. 2020). However, research is needed to assess whether implementing SWAP influences which products clients select from the shelves. Therefore, the aim of the current study is to assess the nutritional quality of the foods selected by clients at a pantry shortly before and after implementing SWAP.

\section{Methods}

\section{Study setting}

A suburban food pantry in the Northeast US planned to implement the SWAP system in May 2019, providing an opportunity to conduct a pre-post comparison study. The pantry invited clients to visit once per week and choose a specific number of items within each food category based on household size. The pantry employed "client choice," meaning that clients selected the specific items they wanted from the pantry shelves, as one would in a grocery store. The client choice model was in place both before and after SWAP implementation. For simplicity, pre-SWAP data collection is referred to as time 1 and the post-SWAP data collection as time 2. Time 1 data collection occurred in May 2019 over five days within the two weeks prior to SWAP implementation. No data were collected for two weeks following the reopening of the pantry. Time 2 data were collected in June-July 2019 over seven days, between three and five weeks after SWAP implementation.

\section{Implementing SWAP}

Staff from the local food bank provided training to pantry staff and volunteers on how to rank food using SWAP. They provided materials and supplies, and made suggestions for implementing the system with the pantry layout. The pantry closed for a few days over a holiday weekend to implement SWAP. Pantry staff and volunteers ranked food according to SWAP, reorganized the placement of food on shelves based on SWAP rankings, and added SWAP shelf tags and signage. For example, the section for soup was reorganized so the "choose often" (green) soups were at eye level, and then the "choose sometimes," and "choose rarely" (red) soups were on a shelf below. All shelves were labeled with the appropriate green, yellow, or red shelf tags. Additional nutrition education was added; for example, signage near canned vegetables suggesting rinsing canned foods to reduce the sodium content. The placement of food was also adjusted to promote healthy food. A display of snacks near the check-in counter was replaced with fresh vegetables as a behavioral "nudge" (Wilson et al. 2017).

\section{Pantry inventory assessment}

SWAP implementation may encourage pantries to increase the availability of healthy foods and decrease unhealthy foods in their inventory, thereby shifting the choices available to clients. To ensure that any changes in client food selection were not solely due to changes in the foods available at the pantry following SWAP implementation, a brief food inventory assessment was conducted over nine days (three days during time 1 and six days during time 2). The number of items available for each of the SWAP food groups (e.g., fruits and vegetables, grains, dairy, etc.) and each of the three SWAP ranks (green, yellow, and red) was rated using the following five-point 0 to 4 scale: none (no items) $=0$; very little $(1$ to 5 items $)=1$; few $(6$ to 15 items $)=2$; several $(16$ to 29 items $)=3$; and a lot $(30$ or more items $)=4$.

\section{Client data collection and measures}

A convenience sample of pantry clients was invited to participate by a research team member or pantry volunteer as clients entered the pantry. After participants finished shopping, they were asked to complete a survey to collect their demographic information while members of the research team recorded the food items they selected. No identifying information was collected from participants during either time period. The client 
survey information included the number of adults and children in the household, age, gender, race and ethnicity, education, income, and participation in government food assistance programs.

To assess the SWAP rank, research staff scanned a food's universal product code (UPC) using WellSCAN, a web-based application that reads the barcode and returns an item's SWAP rank (WellSCAN). Research staff first selected the food's category (e.g., "protein" for a can of beans), then scanned the item. WellSCAN retrieves nutrition information from a database, then calculates a SWAP ranking based on the amount of saturated fat, sodium, and sugar in the food. For example, a can of beans with $0 \mathrm{~g}$ of saturated fat, $460 \mathrm{mg}$ of sodium, and $1 \mathrm{~g}$ of sugar per serving would be ranked as yellow: the saturated fat value falls below the maximum of $2 \mathrm{~g}$ for a green ranking in the "protein" category; the sodium value falls between $200 \mathrm{mg}$ and $480 \mathrm{mg}$, ranking it yellow; and the sugar value falls below the maximum of $5 \mathrm{~g}$ for a green ranking. The food's final ranking is based on the lowest value of its individual nutrient rankings (i.e., saturated fat, sodium, and sugar); therefore, the can of beans would be ranked as yellow. For a complete listing of the SWAP nutrition standards used in this pilot, see Cooksey-Stowers et al. (2020). As a note, the SWAP standards have recently been revised to align with Healthy Eating Research Nutrition Guidelines for the Charitable Food System, published in 2020 (Schwartz et al. 2020). Researchers photographed any items without UPCs (e.g., fresh produce) and used publicly available nutrition information to calculate the SWAP rank.

\section{Analysis plan}

Client demographics Because no identifying information was collected from participants, the time 1 (pre-SWAP) and time 2 (post-SWAP) clients were treated as independent samples. The demographic data from both samples were summarized in means and percentages, and tested for significant differences using independent t-tests for continuous variables and chi-square (test for homogeneity) for categorical variables.

Food pantry inventory Regression analyses were used to assess changes from pre to post in the inventory ratings for each SWAP rank (i.e., green, yellow, and red). The models defined the inventory ratings as the outcome; SWAP rank, time, and the interaction of SWAP rank and time as predictors; and food type (e.g., dairy, grain) as a fixed effect.

Nutritional quality of client carts The proportion of green, yellow, and red items overall, and for each food group, was calculated. The hypothesis was that green selections would increase and red selections would decrease; therefore, the proportion of green and red selections were the outcomes of interest. The proportions were examined for normality using normal quantile plots, skewness, and kurtosis. The overall proportion of clients' selections were normally distributed; however, the proportion of clients' green and red selections separated by food type did not meet the assumption of normality. Thus, two strategies were used. Changes in the selection of green and red items within specific food types were assessed using Wilcoxon rank-sum non-parametric tests. Changes in the proportion of green and red foods with all food types combined were assessed using two linear regression models. The independent variable was time (pre-SWAP or post-SWAP) and the dependent variables were the proportion of green items in model 1 and the proportion of red items in model 2. All models included covariates (gender, age, race, education, income, and participation in government food assistance programs).

To test whether the observed changes in client food selection were influenced by daily changes in food pantry inventory, a second set of two adjusted regression analyses was conducted that controlled for the inventory. Specifically, the daily average red or green inventory data from each of the time 1 and time 2 data collection days were matched with the appropriate client-level data from the same days. Because pantry inventory data were assessed for nine of the 12 days (pre: $n=3$ and post: $n=6$ ), the adjusted model only included clients from days with corresponding inventory data $(n=149)$. All data were analyzed in SAS 9.4 (SAS Institute Inc. Cary, NC) or STATA 16 (StataCorp LLC. College Station, TX) and significance was set at $p<0.05$.

\section{Results}

Table 1 presents the demographic variables for clients pre$(n=121)$ and post- $(n=101)$ SWAP. Pre-SWAP, participants selected a mean of 24.3 items $(\mathrm{SD}=10.9)$ and post-SWAP, participants selected a mean of 22.1 items $(\mathrm{SD}=11.5)$. No statistically significant differences were observed in any of the participant characteristics between the pre- and postSWAP samples.

There was a main effect for SWAP rank $(t=-3.06$, $p=.003)$ on pantry inventory scores. The number of items available increased as the nutritional ranking improved: red $M=2.07$ (.35), yellow $M=2.75$ (.35), and green $M=2.80$ (.35). There was not a significant main effect for time nor an interaction between time and SWAP rank, suggesting that the overall amount of inventory and amount of inventory per SWAP rank remained consistent after SWAP was implemented.

Table 2 presents the findings from the two regression models testing the changes in the proportion of green and red items in client baskets. The unadjusted results indicate that the average proportion of items ranked green increased significantly by $11 \%$ from pre- to post-intervention, while the 
Table 1 Client demographics for pre- and post-SWAP samples

\begin{tabular}{|c|c|c|}
\hline Variable (pre-SWAP sample n, post-SWAP sample n) ${ }^{a}$ & $\begin{array}{l}\text { Pre-SWAP } \\
(n=121) \\
\text { Mean } \pm \text { SD or }(\%)^{b}\end{array}$ & $\begin{array}{l}\text { Post-SWAP } \\
(n=101) \\
\text { Mean } \pm \text { SD or }(\%)^{b}\end{array}$ \\
\hline \multicolumn{3}{|l|}{ Adults in home $(113,94)$} \\
\hline 1 & 46.9 & 58.5 \\
\hline 2 & 38.1 & 31.9 \\
\hline$>2$ & 15.0 & 9.6 \\
\hline \multicolumn{3}{|l|}{ Children in home $(110,93)$} \\
\hline 0 & 70.9 & 76.3 \\
\hline $1-2$ & 20.8 & 14.0 \\
\hline$>2$ & 8.2 & 9.7 \\
\hline Age $(119,97)$ & $55.5 \pm 16.6$ & $55.0 \pm 15.5$ \\
\hline \multicolumn{3}{|l|}{ Income $(110,95)$} \\
\hline$\leq \$ 10,000$ & 27.3 & 32.6 \\
\hline$\$ 10,001-\$ 20,000$ & 40.0 & 42.1 \\
\hline$\$ 20,001-\$ 35,000$ & 27.3 & 20.0 \\
\hline$\geq \$ 35,000$ & 5.5 & 5.3 \\
\hline \multicolumn{3}{|l|}{ Education $(116,90)$} \\
\hline$\leq$ High school & 54.3 & 55.2 \\
\hline$>$ High school & 45.7 & 44.8 \\
\hline \multicolumn{3}{|l|}{ Gender $(119,90)$} \\
\hline Female & 74.0 & 66.7 \\
\hline Male & 29.2 & 33.3 \\
\hline \multicolumn{3}{|l|}{ Race/ethnicity $(118,96)$} \\
\hline White Non-Hispanic & 81.4 & 77.1 \\
\hline Hispanic & 3.4 & 3.1 \\
\hline Black Non-Hispanic & 9.3 & 3.1 \\
\hline Asian & 1.7 & 2.1 \\
\hline American Indian & 0.0 & 2.1 \\
\hline Multi-racial & 3.4 & 6.3 \\
\hline Others & 0.9 & 6.3 \\
\hline
\end{tabular}

${ }^{\text {a }}$ Values vary due to missing data

b There were no statistically significant differences between any variables in pre- and post-SWAP samples average proportion of clients' red selections decreased significantly by $7 \%$ from pre- to post-intervention $\left(R^{2}=9 \%\right.$ and $R^{2}=7 \%$, respectively). In the adjusted model, the observed changes remained statistically significant with a $12 \%$ increase in green and an $8 \%$ decrease in red after controlling for the food pantry's overall green and red food inventory on the same days $\left(R^{2}=13 \%\right.$ and $R^{2}=11 \%$, respectively). No
Table 2 Summary of regression for proportion of clients' food selection pre- and post-SWAP implementation $^{\mathrm{a}}$

\begin{tabular}{|c|c|c|c|c|}
\hline \multirow[t]{4}{*}{ Variable } & \multicolumn{2}{|l|}{ Green items } & \multicolumn{2}{|l|}{ Red items } \\
\hline & $\begin{array}{l}\text { Unadjusted model } \\
(N=222)\end{array}$ & $\begin{array}{l}\text { Adjusted model } \\
(n=149)\end{array}$ & $\begin{array}{l}\text { Unadjusted model } \\
(N=222)\end{array}$ & $\begin{array}{l}\text { Adjusted model }{ }^{\mathrm{b}} \\
(n=149)\end{array}$ \\
\hline & $R^{2}=9 \%$ & $R^{2}=13 \%$ & $R^{2}=7 \%$ & $R^{2}=11 \%$ \\
\hline & $\beta(\mathrm{SE})$ & $\beta(\mathrm{SE})$ & $\beta(\mathrm{SE})$ & $\beta(\mathrm{SE})$ \\
\hline Post SWAP & $0.11(0.02)^{* * * *}$ & $0.12(0.03)^{* * * *}$ & $-0.07(0.02)^{* * *}$ & $-0.08(0.02)^{* * * *}$ \\
\hline
\end{tabular}

$(* * * p<0.001)$

${ }^{\text {a }}$ Reference category: pre-SWAP

b Adjusted model: controlling for food pantry inventory 
significant effect of any of the covariates was observed in the models.

Table 3 presents the findings from the Wilcoxon signedrank test comparing the proportion of green and red foods selected for each food type. Post-SWAP, the proportion of green fruits and vegetables $(p<0.001)$ and dairy $(p<0.001)$ significantly increased, whereas the proportion of red fruits and vegetables $(p<0.001)$ and combination meals $(p<0.001)$ significantly decreased. However, the selection of green condiments also decreased significantly $(p<0.001)$ and red beverages $(p<0.001)$ and condiments $(p<0.001)$ increased. To illustrate these findings, Fig. 1 presents the count of green, yellow, and red items selected for each food category pre- and post-SWAP, standardized to 100 clients for ease of comparison.

\section{Discussion}

This study supports the hypothesis that implementing a system such as SWAP can help clients select a healthier basket of foods in a client-choice pantry. These findings are consistent with other recent studies in the food pantry setting. Grabow et al. (2020) found that rearranging the pantry shelves to highlight foods such as fresh fruit and vegetables increased client selections of these products. Similarly, Caspi et al. (2019) found that the nutritional quality of clients' selections improved following a multicomponent approach that included increasing access to healthy foods and using placement to highlight healthier options.

Notably, client selections improved even though the nutrition profiles of the food pantry inventory remained consistent before and after SWAP implementation. Cooksey-Stowers et al. (2020) examined the inventory in six food pantries after one year of implementing SWAP and found a significant

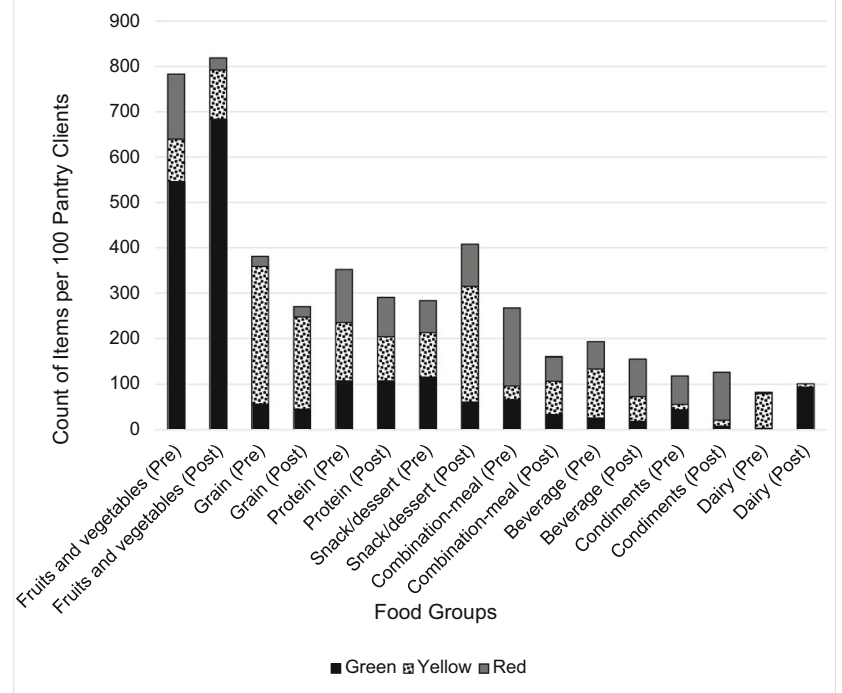

Fig. 1 Number of green, yellow, and red items for each food group selected by clients pre- and post-SWAP implementation

increase in green food, suggesting the experience of using SWAP shifts decisions by pantry managers. The lack of change in our data may be because the current study assesses immediate changes after SWAP implementation, as opposed to a full year later. Our inventory data also indicate that even before the intervention, green items outnumbered red items in the pantry. It is possible that this food pantry had already prioritized supplying healthier options, which might also have led to their interest in implementing SWAP. Notably, our findings support the hypothesis that SWAP can improve client selection beyond the effects of greater access and availability of healthier foods.

These findings contribute to the literature on interventions to increase fruit and vegetable consumption among lowincome populations (Gans et al. 2016; Long 2019; Young 2013). It was encouraging to observe that clients in the post-
Table 3 Changes in the proportion of green and red items selected by food group ${ }^{\text {a }}$

\begin{tabular}{|c|c|c|c|c|}
\hline & \multicolumn{2}{|l|}{ Green } & \multicolumn{2}{|l|}{ Red } \\
\hline & Pre-SWAP & Post-SWAP & Pre-SWAP & Post-SWAP \\
\hline Fruits and vegetables & $0.67(0.42)$ & $0.86(0.33)^{* * *}$ & $0.19(0.33)$ & $0.00(0.00)^{* * * *}$ \\
\hline Grains & $0.00(0.25)$ & $0.00(0.25)$ & $0.00(0.00)$ & $0.00(0.00)$ \\
\hline Proteins & $0.25(0.50)$ & $0.33(0.60)^{*}$ & $0.33(0.50)$ & $0.25(0.50)$ \\
\hline Dairy & $0.00(0.00)$ & $1.00(0.00)^{* * *}$ & $0.00(0.00)$ & $0.00(0.00)$ \\
\hline Snacks/desserts & $0.38(0.83)$ & $0.33(0.50)$ & $0.00(0.50)$ & $0.00(0.50)$ \\
\hline Beverages & $0.00(0.00)$ & $0.00(0.00)$ & $0.00(0.50)$ & $0.50(1.00)^{* * * *}$ \\
\hline Combination foods & $0.00(0.45)$ & $0.00(0.33)$ & $0.67(0.50)$ & $0.29(0.94)^{* * * *}$ \\
\hline Condiments & $0.00(0.67)$ & $0.00(0.00)^{* * *}$ & $0.50(1.00)$ & $1.00(0.33)^{* * * *}$ \\
\hline
\end{tabular}

Comparisons were performed for the proportion of clients' selection by food groups using Wilcoxon signed-rank test. $(* * * p<0.001, * * p<0.01, * p<0.05)$

a Values are the median and interquartile range (IQR) of proportion of clients' selection per food group 
SWAP group selected a higher proportion of green fruits and vegetables and a lower proportion of red fruits and vegetables. One strength of SWAP is that canned fruits and vegetables are arranged on shelves by nutrition rank, which allows clients to quickly and easily identify canned fruit with lower sugar levels and canned vegetables with lower sodium levels. There was also a significant decrease in red client selections within the combination food type - these are primarily soups and canned pasta meals. Again, this may be because SWAP allowed clients to quickly identify the products that were high in sugar, sodium, or saturated fat, and thus not select them.

Contrary to our hypothesis, clients increased their selection of red condiments and beverages post-SWAP. This result runs counter to evidence from a systematic review that found that traffic light labeling is associated with decreases in sales of sugar-sweetened beverages (von Philipsborn et al. 2019). This may be due to unanticipated factors that may influence the consumption of beverages. Specifically, several of the days when the post-SWAP data collection took place were particularly hot and humid. Increasing the availability of cold water and limiting soft drinks may be a useful intervention during the summer months. Relatedly, a specific red condiment such as ketchup may have been particularly appealing during the time 2 period close to the Fourth of July. Future qualitative research may be useful to develop a more nuanced understanding of why clients select specific items, and exploring choices seasonally, during specific times of the year.

A recent national survey of food bank directors found that more than half reported using a tracking system to assess the nutritional quality of inventory, and doing so was associated with healthier inventory overall (Feldman and Schwartz 2018). Further, Feeding America, a nationwide network of approximately 200 food banks, recently recognized the value of a stoplight nutrition ranking system developed by a national expert panel (Feeding America 2020; Schwartz et al. 2020). If food banks across the country share nutrition rankings with those who procure food for their partner pantries, then that information can be utilized in the pantry setting to guide client selections.

\section{Strengths and limitations}

The strengths of this study include the detailed measurement of individual client baskets and the use of inventory ratings as a control variable in the primary outcome analyses. This study also has limitations. First, in order to maintain client anonymity, we did not collect any identifying information; therefore, we could not match client data from pre- and post-implementation, nor could we confirm how many clients participated in both rounds of data collection. A second limitation concerns the measurement of pantry inventory, which only provided an approximation of the number of items at the beginning of the day. Pantry inventory changes while the pantry is open because clients take items and new deliveries arrive. In addition, it was not logistically feasible to complete the pantry inventory every day of data collection. As a consequence, the adjusted analyses were restricted to the smaller sample that had inventory and client basket data from the same day. However, the findings of the adjusted and unadjusted regressions were very similar, suggesting that inventory changes were not a major factor in the current study. Third, the majority of the pantry clients in this study are white, middle-aged women who had no children in the home. Thus, the findings may not be generalizable to other demographics. Finally, a fourth limitation is that this study was conducted at a single client-choice pantry in a suburban area. There is variability in how different food pantries operate and future research is needed to identify the characteristics of pantries best suited for SWAP.

\section{Directions for future research}

The current study was designed as a pilot test of the SWAP intervention and our findings show that SWAP may help food pantry clients choose healthier foods. However, future studies will need to assess the extent to which SWAP improves client food selection across multiple food pantries. Designs of such studies should also address the practical issues we encountered in our pilot testing.

First, we did not track clients by collecting personally identifying information, out of consideration for their status as members of a vulnerable population. We gave each client a business card with a randomly assigned identification number during time 1 data collection, and asked clients to retain the card and present it when we returned for time 2 data collection. This would allow us to match clients' carts at time 1 and time 2, without needing to collect clients' names or other sensitive information. While many clients returned with their cards, many others misplaced or forgot to bring their cards with them. Others could not remember if they had participated in our study previously. As a result, we could not be certain that participants with data from only one time point were truly new participants. If researchers wish to compare pre- and postSWAP carts within participants, they will need to track clients by name or another identifier.

Second, we found that the internet connection at the food pantry was not always reliable; therefore, the WellSCAN program had to be updated to ensure that all items from all scanned carts were saved. Future studies should use the updated version of WellSCAN.

Finally, our pilot study used a convenience sample of clients, collected over a few months during a single season. Future studies should randomly select clients to shop in either SWAP or non-SWAP pantries across multiple seasons to account for seasonality. 


\section{Conclusion}

These findings highlight the potential of using a stoplight nutrition ranking system that is consistent with a larger national movement to improve nutrition quality across the entire food banking network. To build the research evidence on the use of nutrition ranking in pantries to influence client choices, a randomized controlled trial of the SWAP system in which the same clients are identified and followed over time is needed. Future research can also examine if healthier selections in the pantry increase healthy food-related decisions in other settings, such as grocery stores. Finally, the ultimate goal is to improve diet-related health outcomes. Future studies can examine how a system such as SWAP can support pantry clients with diet-related diseases such as diabetes, hypertension, and obesity.

Acknowledgments The authors thank the Rudd Center research staff, Jaime Foster, Ph.D., Madeleine Aseltine, Tanvi Patel, Casey Cunningham, and the staff and clients from Hockanum Valley Community Council.

Authors' contributions All authors contributed to this paper. MS and KM designed and oversaw the study; SM and EG collected and processed the data; AA processed the data and conducted data analyses; RX designed and conducted analyses. All authors contributed to the writing and substantive review of the manuscript. All authors have read and approved this manuscript.

Funding This study was funded by a grant from the University of Connecticut Institute for Collaboration, Health, Intervention, and Policy.

Availability of data and material The datasets generated and analyzed during the current study are available from the corresponding author on reasonable request.

\section{Declarations}

Ethics approval All protocols associated with this study were approved by the University of Connecticut Institutional Review Board.

Consent to participate Verbal consent was obtained from all participants included in the study.

Consent for publication Verbal consent for publication was obtained from all participants included in the study.

Conflict of interest The authors have no conflicts of interest to disclose.

Open Access This article is licensed under a Creative Commons Attribution 4.0 International License, which permits use, sharing, adaptation, distribution and reproduction in any medium or format, as long as you give appropriate credit to the original author(s) and the source, provide a link to the Creative Commons licence, and indicate if changes were made. The images or other third party material in this article are included in the article's Creative Commons licence, unless indicated otherwise in a credit line to the material. If material is not included in the article's Creative Commons licence and your intended use is not permitted by statutory regulation or exceeds the permitted use, you will need to obtain permission directly from the copyright holder. To view a copy of this licence, visit http://creativecommons.org/licenses/by/4.0/.

\section{References}

Andreyeva T, Tripp AS, Schwartz MB (2015) Dietary quality of Americans by supplemental nutrition assistance program participation status: a systematic review. Am J Prev Med 49(4):594-604. https://doi.org/10.1016/j.amepre.2015.04.035

Bhattarai GR, Duffy PA, Raymond J (2005) Use of food pantries and food stamps in low-income households in the United States. J Consum Aff 39(2):276-298. https://doi.org/10.1111/j.1745-6606. 2005.00015.x

Caspi CE, Canterbury M, Carlson S, Bain J, Bohen L, Grannon K, Peterson H, Kottke T (2019) A behavioural economics approach to improving healthy food selection among food pantry clients. Public Health Nutr 22(12):2303-2313. https://doi.org/10.1017/ S1368980019000405

Coleman-Jensen A, Rabbitt MP, Gregory CA, Singh A (2018) Household food security in the United States in 2018. ERR-270, USDA Economic Research Service. https://www.ers.usda.gov/ publications/pub-details/?pubid=94848

Cooksey-Stowers K, Martin KS, Schwartz M (2019a) Client preferences for nutrition interventions in food pantries. J Hunger Environ Nutr 14(1-2):18-34. https://doi.org/10.1080/19320248.2018.1512929

Cooksey-Stowers K, Read M, Wolff M, Martin KS, McCabe M, Schwartz MB (2019b) Food pantry staff attitudes about using a nutrition rating system to guide client choice. J Hunger Environ Nutr 14(1-2):35-49. https://doi.org/10.1080/19320248.2018. 1512930

Cooksey-Stowers K, Martin KS, Read M, McCabe M, Cornelius T, Wolff M, Xu R, Schwartz MB (2020) Supporting wellness at pantries (SWAP): changes to inventory in six food pantries over one year. J Public Health (Berl). https://doi.org/10.1007/s10389-02001350-8

Daponte BO (2000) Private versus public relief: use of food pantries versus food stamps among poor households. J Nutr Educ 32(2): 72-83. https://doi.org/10.1016/S0022-3182(00)70523-1

Duffy P, Zizza C, Jacoby J, Tayie FA (2009) Diet quality is low among female food pantry clients in eastern Alabama. J Nutr Educ Behav 41(6):414-419. https://doi.org/10.1016/j.jneb.2008.09.002

Feeding America (2020) Leading health experts release guidelines to increase access to healthy food and beverages in food banks. https://www.feedingamerica.org/about-us/press-room/ guidelines-increase-access-healthy-food. Accessed 12 May 2021

Feldman M, Schwartz, M (2018) A tipping point leveraging opportunities to improve the nutritional quality of food bank inventory. https:// mazon.org/wp-content/uploads/MAZON-Report-TippingPoint.pdf. Accessed 12 May 2021

Gans KM, Gorham G, Risica PM, Dulin-Keita A, Dionne L, Gao T, Peters S, Principato L (2016) A multi-level intervention in subsidized housing sites to increase fruit and vegetable access and intake: rationale, design and methods of the "live well, viva Bien" cluster randomized trial. BMC Public Health 16:521. https://doi.org/10. 1186/s12889-016-3141-7

Grabow KN, Schumacher J, Banning J, Barnes JL (2020) Highlighting healthy options in a food pantry setting: a pilot study. Fam Consum Sci Res J 48:263-275. https://doi.org/10.1111/fcsr.12348

Huerbin S, Strauch J, Brecht C, Zwolenik KA, Lenhart CM (2019) Helping or harming? Review of nutrition quality of Monroe 
County food pantry holdings. J Hunger Environ Nutr 15(4):473483. https://doi.org/10.1080/19320248.2019.1615592

Long CR (2019) Intervention to improve access to fresh fruits and vegetables among Arkansas food pantry clients. Prev Chronic Dis 16: 180155. https://doi.org/10.5888/pcd16.180155

Martin KS, Wu R, Wolff M, Colantonio AG, Grady J (2013) A novel food pantry program: food security, self-sufficiency, and dietquality outcomes. Am J Prev Med 45(5):569-575. https://doi.org/ 10.1016/j.amepre.2013.06.012

Martin KS, Wolff M, Callahan K, Schwartz MB (2019) Supporting wellness at pantries: development of a nutrition stoplight system for food banks and food pantries. J Acad Nutr Diet 119(4):553-559. https:// doi.org/10.1016/j.jand.2018.03.003

Robaina KA, Martin KS (2013) Food insecurity, poor diet quality, and obesity among food pantry participants in Hartford, CT. J Nutr Educ Behav 45(2):159-164. https://doi.org/10.1016/j.jneb.2012.07.001

Schwartz MB, Seligman HK (2019) The unrealized health-promoting potential of a national network of food pantries. J Hunger Environ Nutr 14(1-2):1-3. https://doi.org/10.1080/19320248.2019.1569819

Schwartz MB, Levi R, Lott M, Arm K, Seligman H (2020) Healthy eating research nutrition guidelines for the charitable food system. NC: Healthy Eating Research, Durham. https://healthyeatingresearch. org:443/research/healthy-eating-research-nutrition-guidelines-forthe-charitable-food-system/

Seligman HK, Lyles C, Marshall MB, Prendergast K, Smith MC, Headings A, Bradshaw G, Rosenmoss S, Waxman E (2015) A pilot food bank intervention featuring diabetes-appropriate food improved glycemic control among clients in three states. Health Aff (Millwood) 34(11):1956-1963. https://doi.org/10.1377/hlthaff. 2015.0641

Simmet A, Depa J, Tinnemann P, Stroebele-Benschop N (2017a) The dietary quality of food pantry users: a systematic review of existing literature. J Acad Nutr Diet 117(4):563-576. https://doi.org/10. 1016/j.jand.2016.08.014

Simmet A, Depa J, Tinnemann P, Stroebele-Benschop N (2017b) The nutritional quality of food provided from food pantries: a systematic review of existing literature. J Acad Nutr Diet 117(4):577-588. https://doi.org/10.1016/j.jand.2016.08.015

USDA ERS (2019) Food security in the U.S.: Key statistics \& graphics. https://www.ers.usda.gov/topics/food-nutritionassistance/food-security-in-the-us/key-statistics-graphics.aspx. Accessed 12 May 2021

von Philipsborn P, Stratil JM, Burns J, Busert LK, Pfadenhauer LM, Polus S, Holzapfel C, Hauner H, Rehfuess E (2019) Environmental interventions to reduce the consumption of sugarsweetened beverages and their effects on health Cochrane Database Syst Rev 6:CD012292. https://doi.org/10.1002/ 14651858.CD012292.pub2

Walker RE, Keane CR, Burke JG (2010) Disparities and access to healthy food in the United States: a review of food deserts literature. Health Place 16(5):876-884. https://doi.org/10.1016/j.healthplace.2010.04. 013

Weinfield N, Mills G, Borger C, Gearing M, Macaluso T, Montaquila J, Zedlewski S (2014) Hunger in America 2014: a report on charitable food distribution in the United States in 2013. Feeding America. http://help.feedingamerica.org/HungerInAmerica/hunger-inamerica-2014-full-report.pdf. Accessed 12 May 2021

WellSCAN. Available at: https://wellscan.io. Accessed 12 May 2021

Wilson NL, Just DR, Swigert J, Wansink B (2017) Food pantry selection solutions: A randomized controlled trial in client-choice food pantries to nudge clients to targeted foods. J Pub Health 39(2):366-372. https://doi.org/10.1093/pubmed/fwd043

Young CR (2013) Improving fruit and vegetable consumption among low-income customers at farmers markets: Philly food bucks, Philadelphia, Pennsylvania, 2011. Prev Chronic Dis 10:120356. https://doi.org/10.5888/pcd10.120356

Publisher's note Springer Nature remains neutral with regard to jurisdictional claims in published maps and institutional affiliations. 